\title{
CORRIGENDUM
}

\section{The JAK inhibitor AZD1480 regulates proliferation and immunity in Hodgkin lymphoma}

E Derenzini, M Lemoine, D Buglio, H Katayama, Y Ji, RE Davis, S Sen and A Younes

Blood Cancer Journal (2014) 4, e231; doi:10.1038/bcj.2014.57; published online 1 August 2014

Correction to: Blood Cancer Journal (2011) 1, e46; doi:10.1038/bcj. 2011.46; published online 2 December 2011

Since the publication of their article, the authors have identified errors in Figures 2 and 5 owing to errors in figures assembly.

In Figure 2c, the caspase 9 panel of the HDLM2 cell line and L-428 cell line are inadvertently duplicated. Similarly, Figure $5 \mathrm{c}$ included duplicate or incorrect panels of donor control blots.

a

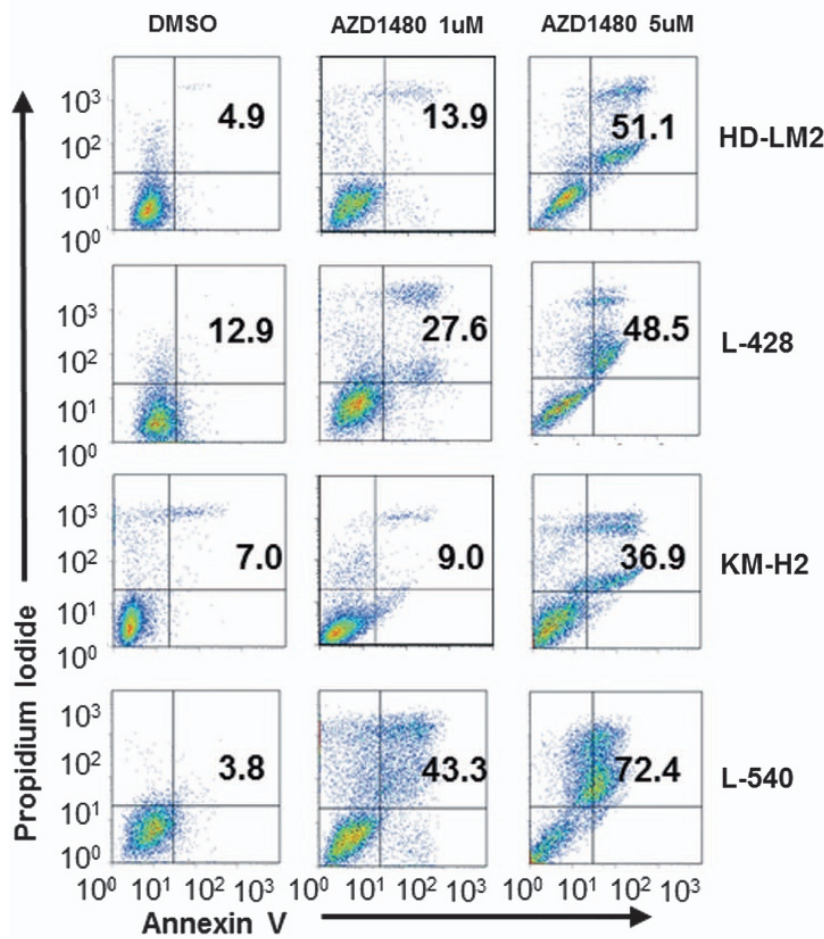

Some panels of the control cell lines in Figure $5 \mathrm{c}$ could not be retrieved to revise the original figure. The authors have therefore provided a corrected Figure $2 \mathrm{c}$ and are replacing the published Figure $5 c$ with a repeat independent experiment. These are shown here.

These errors have no impact on the results. There is no change in the text or figure legends.

The authors wish to apologise for any inconvenience caused.

b
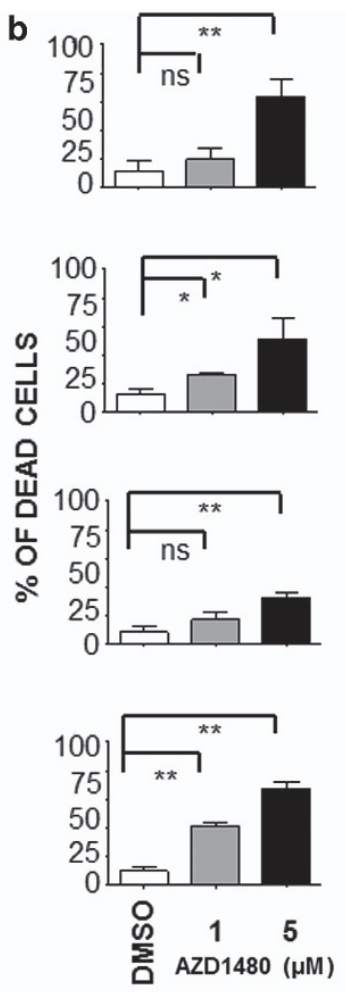

C $\overline{\frac{5}{n}}$
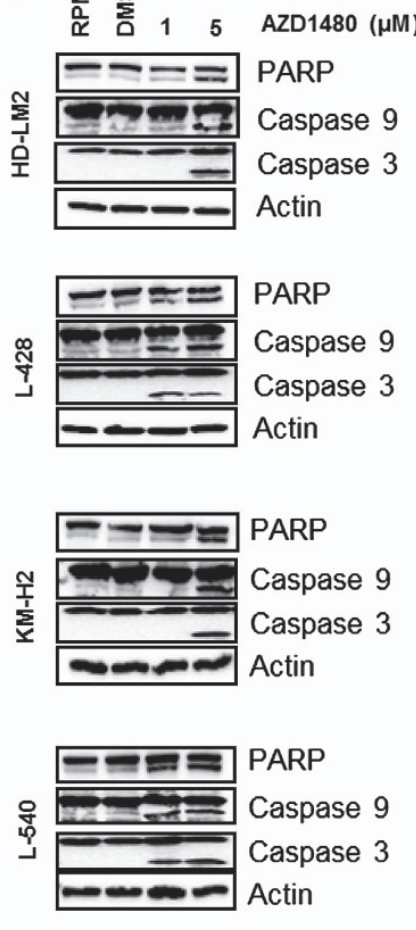

Figure 2. AZD1480 induces apoptosis in $\mathrm{HL}$ cell lines. (a) Representative experiment demonstrating the effect of two different doses of AZD1480 ( 1 or $5 \mu \mathrm{m}$ for $72 \mathrm{~h}$ ) on apoptosis as determined by annexin V-binding assay. The percentage of dead cells is shown in the upper right quadrant. (b) Summary of the results of dual annexin V and propidium iodide (PI) staining. Each value is the mean of three independent experiments performed in triplicate. ${ }^{*} P<0.05 ;{ }^{*} P<0.005$; NS, not significant. Error bars represent s.e.m. (c) Immunoblotting showing activation of the intrinsic apoptotic pathway in $\mathrm{HL}$ cell lines incubated with AZD1480 (1-5 $\mu \mathrm{m})$ for $72 \mathrm{~h}$. Consistent with the data in (a) and (b), cleavage of poly (adenosine diphosphate ribose) polymerase (PARP) and activation of caspases 9 and 3 were observed in all the cell lines exposed to $5 \mu \mathrm{m}$ AZD1480. In L-540 and L-428, caspase cleavage was observed also with $1 \mu \mathrm{m}$ AZD1480. 
a

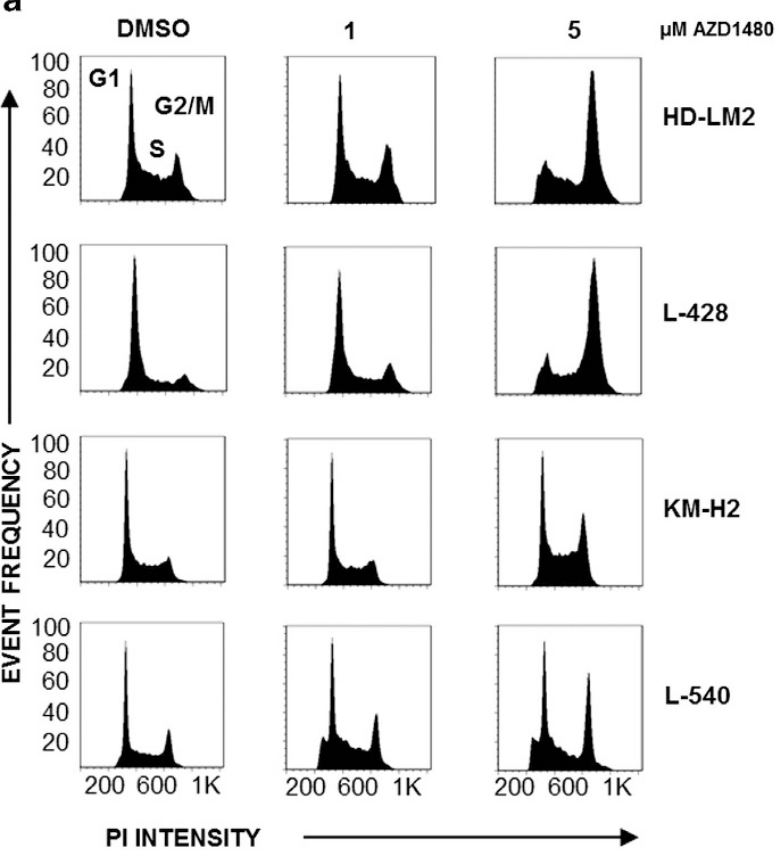

b $\quad$ SUB GO
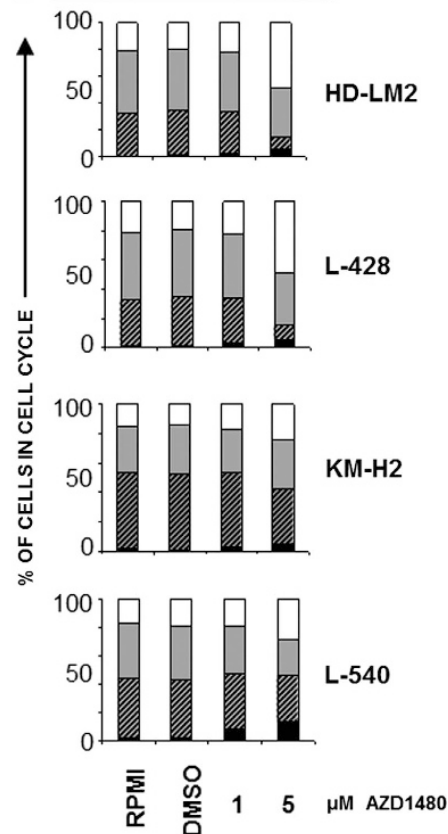

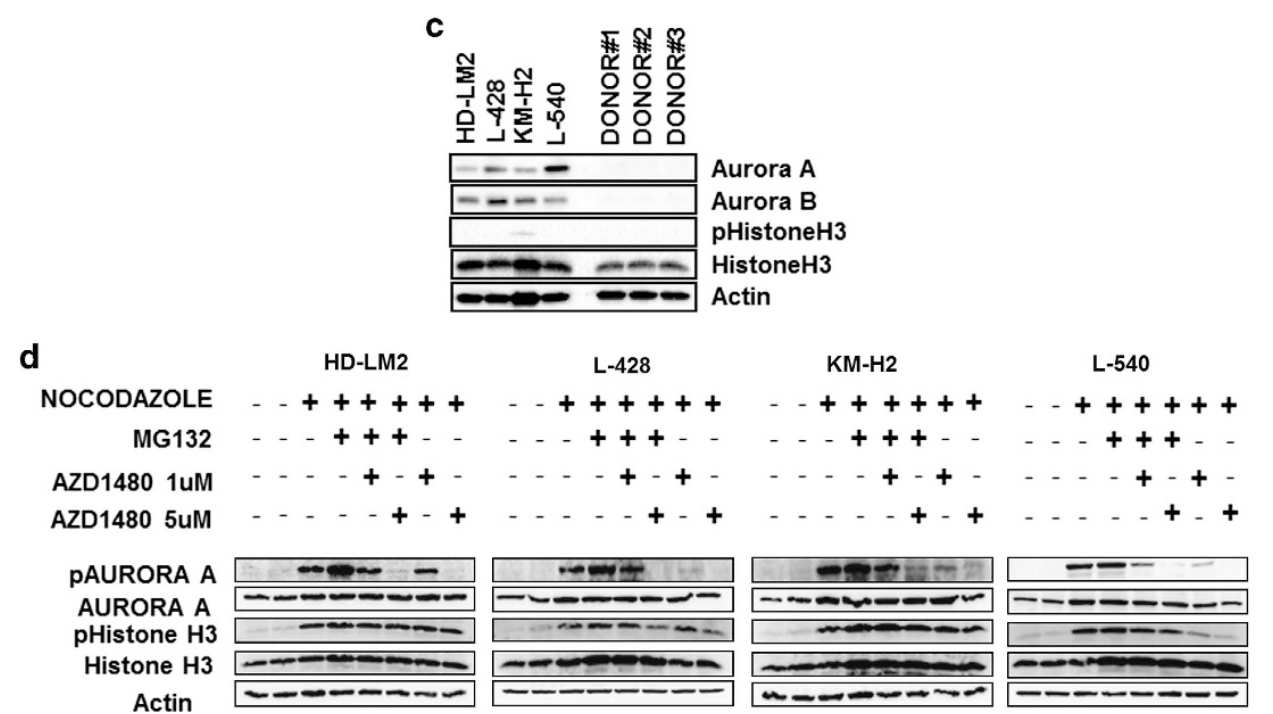

Figure 5. AZD1480 induces G2/M cell cycle arrest by inhibition of Aurora A in HL cell lines. (a) Cells were incubated with AZD1480 (1 or $5 \mu \mathrm{m}$ ) for $24 \mathrm{~h}$, and the cell cycle was analyzed by flow cytometry. AZD1480 induced an increase in the G2/M fraction only when a high concentration $(5 \mu \mathrm{m})$ was used. (b) Bar graphs summarizing cell cycle analysis results; each value is the mean of three independent experiments. (c) Baseline expression status of Aurora kinases and histone $\mathrm{H} 3$ in $\mathrm{HL}$ cell lines. Whole-cell lysates of untreated $\mathrm{HL}$ cells were examined by western blotting for Aurora A, Aurora B, histone H3 and p-histone H3 (Ser10). (d) Representative western blot assay showing the

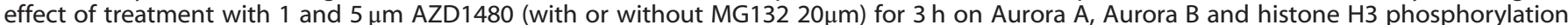
(Ser 10) in HL cells. Cells were pretreated with nocodazole $400 \mathrm{ng} / \mathrm{ml}$ for $18 \mathrm{~h}$ to achieve a mitotic block. 